\title{
A Study of EFL Listening Anxiety in a Test Setting
}

\author{
Hongying $\mathrm{Li}^{1}$ \\ ${ }^{1}$ School of Foreign Languages, Jiangnan University, Wuxi, China \\ Correspondence: Hongying Li, School of Foreign Languages, Jiangnan University, Wuxi, China. E-mail: \\ marialee510@126.com
}

Received: January 15, 2015 Accepted: February 6, 2015 Online Published: March 29, 2015

doi:10.5539/ijel.v5n2p106

URL: http://dx.doi.org/10.5539/ijel.v5n2p106

\begin{abstract}
The present study employed both a quantitative and a qualitative study. It found that English listening anxiety affected most of the subjects in the test and that there was a significantly negative correlation between subjects' English listening anxiety levels and their test performance. The interviews further confirmed that the environmental factors, self-perceived foreign language listening competence, fear of failing the listening course, and beliefs about language learning were reported as four major factors leading to English listening anxiety. This was a correlational study and it was likely that foreign language anxiety and language learning were mutually reinforcing; therefore, it will help students with their learning if the teachers help them foster a positive self-image and right beliefs about language learning.
\end{abstract}

Keywords: anxiety, test, listening, performance, language

\section{Introduction}

Anxiety is a complex psychological construct consisting of many variables. It is difficult to collapse them all into a single concise definition. Linguists have come up defections from various aspects. (Spielberger, 1983; MacIntyre \& Gardner, 1994; Madigan et al., 1996; Sellers, 2000).

Horwitz et al. (1986) proposed that foreign language anxiety be seen as a separate and distinct process particular to second language acquisition. Horwitz et al.'s statement turns out a collection of manifestations ranging across cognitive ("self-perceptions" and "beliefs"), affective ("feelings") and behavioral ("behaviors") domains.

Language teachers and educators contend that anxiety has a detrimental effect on language learning and performance (Young, 1992), but some research shows that this is not necessarily true (MacIntyre, 1991). Researchers distinguished between two types of anxiety: facilitating anxiety and debilitating anxiety. The former motivates the learner in a positive way and is best viewed as enthusiasm. In contrast, the debilitating anxiety, including the unpleasant feelings such as uneasiness and dread, affects the learner's performance negatively in the learning process.

Although there has been an increase of studies on foreign language anxiety in recent years, and, given its important influence on foreign language learning, these previous studies provide many valuable insights, it still leaves some controversy and problems to be solved. For instance, a number of previous studies on foreign language anxiety found a persistent, modest negative correlation between foreign language anxiety and learners' performance, but some declared that anxiety might not be an important variable in foreign language performance, as quite a few correlations computed were not statistically significant. Hence, it is necessary to conduct a study to investigate the very influence anxiety exerts on foreign language learners' performance. Besides, when language is studied in the domain of foreign language learning, the focus is often on the oral mode (Phillips, 1992, Steinberg, 1982; Horwitz \& Young, 1991). Moreover, the relationship between anxiety and language learning performance cannot be viewed without taking into account an assortment of variables, such as language settings (Young, 1991). Much of the research, however, did not pay attention to settings in which foreign language anxiety was aroused. So a study on English listening anxiety in the test setting is needed and significant to enrich the empirical evidence on the topic and offer more insights.

\section{Methodology}

\subsection{Research Questions}

This study was conducted in an English listening test setting. First, a survey design was employed to examine the 
relationship between listening performance and anxiety for EFL students in the listening test. Second, a qualitative design (an interview) was adopted to explore the highly anxious students' own account of their anxiety. To be specific, the study intended to address the following questions:

1) What is the relationship between EFL students' anxiety level and their English listening performance?

2) How do the highly anxious students react during the test?

3) How do the highly anxious students explain why they feel anxious in the test?

\subsection{Quantitative Study}

The subjects were selected through convenience sampling from the English department in a college in Shandong, China. They were 102 first-year English majors from a college in Shandong, China, of whom 13 were male (12.7\%) and 89 were female (87.2\%). Their ages ranged from 16 to 24 , with an average of 20.56 . They had been learning English for 7 to 10 years, with an average English-learning length of 7.52 years.

First, the subjects were asked to gather one evening to do a set of listening comprehension items from PETS-3 and they were informed that it was a test, which would account for 40 percentages of their final score of the listening course. Immediately after the exercise, they were instructed to complete the ELAS, which was specially developed by the researcher to measure the subjects' anxiety level related to English listening, the English Listening Anxiety Scale (ELAS). All of the items were rendered into Chinese so as to make the items easily understood by the students.

It took 20-30 minutes to finish the listening comprehension items and 5-10 minutes to complete the ELAS. All the listening comprehension papers and the questionnaires were collected immediately after the subjects completed them.

As for the listening comprehension test and the questionnaires, the researcher graded them and key-reversed some of the questionnaire items for analysis convenience. Then she input the data into SPSS 11.0 for Windows for later analysis.

\subsection{Qualitative Study}

Eight subjects with the highest ELAS scores were selected to receive an individual interview with the researcher. A semi-structured interview procedure was employed to probe into the cognitive, affective and behavioral anxiety of EFL students in the English listening test. The interview was arranged as:

1) "You experienced comparatively higher anxiety level in the listening comprehension test, could you please describe your feelings and reactions at that moment?"

2) "Why did you feel so anxious during the test?"

The eight interviewees each received an individual interview with the researcher. The researcher paid careful attention to the interviewees' description of their status during the test and consciously dug for useful information. Each interview was recorded by a tape-recorder for later analysis. Finally the interviewees' reported anxious symptoms were extracted, categorized and analyzed.

\section{Results and Discussion}

\subsection{Students Anxiety Levels on the ELAS}

\subsubsection{The Overall Anxiety Levels on the ELAS}

As the result of the data analysis, the average mean score of the whole sample on the ELAS was 2.6885, which identified this group of students as moderately anxious in the listening test. However, the standard deviation of 0.54018 indicated that some portion of the subjects had signs of being non- anxious, albeit there were ones with high level of anxiety.

Regarding the proportion of the anxious and non-anxious students, $66.7 \%$ of the subjects scored higher than 2.5 and $37.3 \%$ lower than 2.5 , which indicated that a majority of the students were affected by anxiety in the English listening test. Table 1 presented the comparisons of overall English listening anxiety levels of the whole sample and the non-anxious and anxious subjects in terms of their average mean scores on the ELAS in the listening test. 
Table 1. The sample's overall English listening anxiety score on the ELAS in the listening test

\begin{tabular}{lllll}
\hline Groups & $\mathrm{N}$ & Percentage & Mean & Std. Deviation \\
\hline Non-anxious & 38 & 37.3 & 2.1192 & .25384 \\
Anxious & 64 & 66.7 & 3.0265 & .34409 \\
Total & 102 & 100 & 2.6885 & .54018 \\
\hline
\end{tabular}

\subsubsection{Three Categories of the English Listening Anxiety}

In this study, the English Listening Anxiety Scale was composed of three components: cognitive symptoms, affective symptoms and behavioral symptoms, of which cognitive symptom consisted of two subcategories: self-perceptions indicators and beliefs indicators.

Table 2. Description of the sample's levels of the three anxiety categories: mean scores, standard deviation

\begin{tabular}{lll}
\hline Categories of ELAS & Mean & Std. Deviation \\
\hline Cognitive symptoms & 2.8627 & .63789 \\
Affective symptoms & 2.7102 & .58610 \\
Behavioral symptoms & 2.3181 & .57279 \\
\hline
\end{tabular}

Note. ELAS $=$ English Listening Anxiety Scale.

Table 3 showed that the three categories were positively correlated with one another with high coefficiency ( $\mathrm{P}=$. 000). Cognitive symptoms as a category including subcategories of self-perceptions indicators and beliefs indicators manifested a mean score of 2.8627 .

Table 3. Correlations of the three categories of the ELAS

\begin{tabular}{lll}
\hline Categories of ELAS & Cognitive symptoms & Affective symptoms \\
\hline \multirow{2}{*}{ Affective symptoms } & $\mathrm{R}=.749$ & \\
& $\mathrm{P}=.000$ & $\mathrm{R}=.426$ \\
\multirow{2}{*}{ Behavioral symptoms } & $\mathrm{R}=.659$ & $\mathrm{P}=.000$ \\
& $\mathrm{P}=.000$ & \\
\hline
\end{tabular}

As shown in Table 4, the mean scores of self-perceptions indicators and beliefs indicators were 3.0893 and 206362, with the former a little higher.

Table 4. Description of the sample's levels of the two subcategories: mean scores, standard deviation

\begin{tabular}{lll}
\hline Variable Name & Mean & SD \\
\hline Self-perceptions & 3.0893 & .67849 \\
Beliefs & 2.6362 & .72062 \\
Cognitive symptoms & 2.8627 & .63789 \\
\hline
\end{tabular}

Although the mean score of the subcategory of beliefs was lower than that of the subcategory of self-perceptions, yet the standard deviation of 0.72062 indicated a possibility that some subject's might have reached beliefs anxiety at the level of more than 3.0893. So it was necessary to see whether the mean scores of each two variables were significantly different. Besides, how the two subcategories of cognitive symptoms were related to each other also remained to be examined. The Paired-Samples T Tests were conducted to see how the students would answer self- perceptions indicators and beliefs indicators and what the relationship between the two subcategories was. The results were presented in Table 5. 
Table 5. Paired-Samples T-tests of anxiety levels of the two subcategories

\begin{tabular}{llllllll}
\hline Category & Sub-category & Mean & SD & Correlation(r) & P & T-value & P \\
\hline \multirow{2}{*}{$\begin{array}{l}\text { Cognitive } \\
\text { symptoms }\end{array}$} & Self-perceptions & 3.0893 & .67849 & \multirow{2}{*}{.663} & \multirow{2}{*}{.000} & \multirow{2}{*}{.7947} & \multirow{2}{*}{.000} \\
\cline { 2 - 5 } & Beliefs & 2.6362 & .72062 & & & & \\
\hline
\end{tabular}

The two variables were significantly different from each other (T-value=7947, $\mathrm{P}=000$ ). Moreover, self-perceptions indicators and beliefs indicators were positively related to each other with a significantly high correlation $(\mathrm{r}=.663, \mathrm{P}=.000)$.

\subsubsection{Discussion}

Foreign language learning is not merely a cognitive process, but also a process of affective activity. The two processes, which work hand in hand with each other, are considered as an integrated system. The subjects' affective symptoms, along with their cognitive symptoms (including self-perceptions and beliefs), contributed most to the foreign language listening anxiety. Most of the students showed affective symptoms which confirmed Krashen's (1992) affective filter hypothesis that language acquisition is greatly influenced by affective filter.

Cognitive symptoms (including self-perceptions indicators and beliefs indicators) boasted of a high mean, which supported Oh's (1990) finding that cognitive interference is a great indicator of foreign language anxiety. Self-perceptions can be seen as a critical factor in language learning anxiety and it plays a key role in how students approach acquisition and use of a second language (Armeda \& Karen, 1988). Similarly, Krashen (1992) suggests that an individual's degree of self-esteem is highly related to language anxiety. Typically students have low self-esteem, perceive themselves as less worthy than others, perceive their communication as less effective than that of their peers, and expect continued failure no matter what feedback they actually receive (McCroskey et al., 1977). So there is no surprise that students exhibited a high mean score of self-perceptions indicators: for example, Item 26 (3.4020), "I was not sure of my answers to the task," Item 32 (3.3529), "I perceived that my listening was poor when I could not follow the task," and Item 8 (3.2157), "I have a small vocabulary and cannot do well in the listening test." The interviewee subjects also confided that they perceived their listening ability was poor and held the idea that others were doing better. Even the one with a high score in the test regarded her own listening to be poor although her classmates thought highly of her listening ability. This proved that both non-successful students and successful ones were devoured by self-perception indicators of anxiety.

Learner beliefs about language learning were a major contributor to language anxiety. As some of the learners' beliefs are unrealistic, they could lead to anxiety. For example, if they believe that they should be fluent in two years, frustration and anxiety will set in. In other words, when beliefs and reality clash, anxiety results (Young, 1991). Likewise, the subjects' beliefs in this study also resulted in high listening anxiety. For instance, Item 21 (2.7745) "I believed that the listening test was difficult when there were some unfamiliar tasks," Item 27 (2.9706) "I believed that we should translate everything into Chinese in order to fully understand the task," and Item 19 (3.4412) "I believed that some people were more able to learn a foreign language than others."

\subsection{Relationship between Subjects' Anxiety Level and Test Performance}

\subsubsection{Relationship between Subjects' Overall Anxiety Level and Test Performance}

To explore the relationship between the subjects' anxiety levels and their listening test performance, correlation analyses were conducted and the results were presented in Table 6.

Table 6. Correlations between the anxiety level and the listening test performance

\begin{tabular}{llll}
\hline Variables & Score of dialogues & Score of conversations & Total listening scores \\
\hline \multirow{2}{*}{ Anxiety levels } & $\mathrm{r}=-.276(* *)$ & $\mathrm{r}=-.211(*)$ & $\mathrm{r}==-.297(* *)$ \\
& $\mathrm{P}=.005$ & $\mathrm{P}=.033$ & $\mathrm{P}=.002$ \\
\hline
\end{tabular}

Note. $* *$ Correlation is significant at the 0.01 level (2-tailed). * Correlation is significant at the 0.05 level (2-tailed).

The findings indicated that the mean scores of the two parts were both significantly and negatively correlated with the anxiety levels, but conversations had a stronger relationship with the anxiety level $(\mathrm{r}=-.276, \mathrm{P}=.005)$ than dialogues $(\mathrm{r}=-.211, \mathrm{P}=.033)$ did, which suggested that students were affected by anxiety in the whole listening process, but were more afflicted when listening to dialogues. 


\subsubsection{Relationship between Subjects' Anxiety Levels of the Three Categories and Test Performance}

As can be seen in Table 7, the three categories were negatively related to the listening test results. The cognitive symptoms $(\mathrm{r}=-.318, \mathrm{P}=.001)$ received a negatively high correlation with the total listening score, indicating that the most of the subjects suffered from cognitive breakdown in the listening test. Affective symptoms also received a negatively significant correlation with the total listening scores $(r=-.243, p<.05)$, showing that the students' nervous feelings might lead to poor listening performance. Behavioral symptoms also proved to have a negative correlation with the total listening scores.

Table 7. Correlations between the three categories of ELAS and the total score of English listening comprehension

\begin{tabular}{llll}
\hline Variables & Cognitive symptoms & Affective symptoms & Behavioral symptoms \\
\hline \multirow{2}{*}{ Total listening scores } & $\mathrm{r}=-.318\left(^{* *}\right)$ & $\mathrm{r}=-.243(*)$ & $\mathrm{r}=-.163$ \\
& $\mathrm{P}=.001$ & $\mathrm{P}=.014$ & $\mathrm{P}=.101$ \\
\hline
\end{tabular}

Note. $* *$ Correlation is significant at the 0.01 level (2-tailed). * Correlation is significant at the 0.05 level (2-tailed).

With respect to the two subcategories of cognitive symptoms, they both boasted of a significance correlation with the total listening scores, with the self-perceptions indicators $(\mathrm{r}=-.321, \mathrm{P}=.001)$ higher than beliefs indicators $(\mathrm{r}=-.261, \mathrm{P}=.008)$ as shows in Table 8.

Table 8. Correlations between the two subcategories of cognitive symptoms and the total score of English listening comprehension

\begin{tabular}{llll}
\hline Variables & Self-perceptions & Beliefs & Cognitive symptoms \\
\hline \multirow{2}{*}{ Total listening scores } & $\mathrm{r}=-.321(* *)$ & $\mathrm{r}=-.261(* *)$ & $\mathrm{r}=-.318(* *)$ \\
& $\mathrm{P}=.001$ & $\mathrm{P}=.008$ & $\mathrm{P}=.001$ \\
\cline { 2 - 3 }
\end{tabular}

The comparison of students' responses to anxiety scales across three groups (high-score, mid-score, and low-score) by using one-way ANOVA can provide a more detailed picture of the relationship.

\subsubsection{Differences in Total Anxiety Means}

Table 9 showed that the total anxiety means showed statistically significant differences across the high-score, mid-score and low-score groups. The total anxiety means increased from 2.4432 to 2.9461 while the test scores decreased from high to low, suggesting an increasing trend of overall anxiety levels with the decrease of the test scores. In other words, the more anxious a subject was, the lower the score he or she received. Moreover, the results showed that either the high-score and mid-score groups or the mid-score and low-score groups did not unfold any significant differences in total anxiety means, whereas the total anxiety means of high-score group was significantly different from that of the low-score group.

Table 9. Differences in total anxiety means across three groups by one-way ANOVA

\begin{tabular}{llllllll}
\hline Variables & Score Level & Mean & SD & High & Mid & F & P \\
\hline \multirow{4}{*}{ Total anxiety } & High & 2.4432 & .56892 & & & & \\
& Mid & 2.7046 & .52547 & & & 4.982 & .009 \\
& Low & 2.9461 & .43926 & $* \mathrm{P}=.000$ & & & \\
\hline
\end{tabular}

Note. $*$ The mean difference if significant at the .05 level.

\subsubsection{Differences in Category Anxiety Means}

Table 10 showed that the means of each of the three categories on ELAS had an increase trend with the decrease of test scores. The means of both cognitive and affective symptoms were statistically significant different across three score groups. In contrast, the category of behavioral symptoms did not show statistically significant differences across the three groups. 
Table 10. Differences in category anxiety means across three groups by ANOVA

\begin{tabular}{|c|c|c|c|c|c|c|c|}
\hline Variables & Score level & Mean & SD & High & Mid & $\mathrm{F}$ & $\mathrm{P}$ \\
\hline \multirow{3}{*}{$\begin{array}{l}\text { Cognitive } \\
\text { symptoms }\end{array}$} & High & 2.5605 & .65261 & & & \multirow{3}{*}{6.226} & \multirow{3}{*}{.003} \\
\hline & Mid & 2.8477 & .63314 & & & & \\
\hline & Low & 3.2045 & .47370 & $* \mathrm{P}=.002$ & & & \\
\hline \multirow{3}{*}{$\begin{array}{l}\text { Affective } \\
\text { symptoms }\end{array}$} & High & 2.4091 & .60702 & & & \multirow{3}{*}{3.918} & \multirow{3}{*}{.023} \\
\hline & Mid & 2.7912 & .57994 & & & & \\
\hline & Low & 2.7980 & .50119 & $* \mathrm{P}=.026$ & & & \\
\hline \multirow{3}{*}{$\begin{array}{l}\text { Behavioral } \\
\text { symptoms }\end{array}$} & High & 2.2424 & .65925 & & & \multirow{3}{*}{2.274} & \multirow{3}{*}{.108} \\
\hline & Mid & 2.2605 & .55323 & & & & \\
\hline & Low & 2.5455 & .49323 & & & & \\
\hline
\end{tabular}

Note. * The mean difference is significant at the .05 level.

The test scores of the three groups decreased from high to low while the means of cognitive symptoms increased from 3.2045 to 2.5605 , showing an increasing trend of cognitive symptoms with the decrease of test scores. The results also manifested that the high-score and mid-score groups did not show any statistically significant difference in cognitive symptoms across three score groups and neither did the mid-score and low-score groups. Contrarily, the cognitive symptoms means of the high-score and low-score groups were significantly different from each other $(\mathrm{P}=.002)$. This indicated that the more successful students were less affected by cognitive symptoms than less successful students in the English listening test.

The test scores of the three groups decreased from high to low while the means of affective symptoms increased from 2.4091 to 2.7980 , showing an increase trend of affective symptoms means with the decrease of test scores. Table 10 also showed that both the high-score and mid-score groups and the mid-score and low-score groups did not unfold any significant differences in the means of cognitive symptoms, but those of the high-score and low-score groups were significantly different from each other $(\mathrm{P}=.026)$. The differences in two subcategories of cognitive symptoms across three score groups are presented Table 11.

Table 11. Differences in two subcategories of cognitive symptoms across three score groups

\begin{tabular}{llllllll}
\hline Variables & Score level & Mean & SD & High & Mid & F & P \\
\hline \multirow{3}{*}{ Self-perceptions } & High & 2.8384 & .67432 & & & & \\
& Mid & 3.0326 & .65056 & & & 6.102 & .003 \\
& Low & 3.4899 & .60632 & $* \mathrm{P}=.004$ & $* \mathrm{P}=.017$ & & \\
\multirow{2}{*}{ Beliefs } & High & 2.2828 & .68983 & & & \multirow{2}{*}{.011} \\
& Mid & 2.6628 & .73555 & & & & \\
\hline \multirow{2}{*}{ Cognitive } & Low & 2.9192 & .58007 & $* \mathrm{P}=.009$ & & & \\
Symptoms & High & 2.4091 & .60702 & & & & \\
& Mid & 2.7912 & .57994 & & & & \\
\end{tabular}

Note. ${ }^{*}$ The mean difference if significant at the .05 level.

The above table showed that both self-perceptions and beliefs indicators of English listening test anxiety as subcategories manifested statistically significant differences across three score groups.

The test scores of the three groups decreased from high to low while the means of self-perceptions indicators increased from 2.8384 to 3.4899 , indicating an increase trend of self-perceptions indicators with the decrease of the test scores. The results also said that both the high-score and low-score groups and the mid-score and low-score groups showed significant differences in the means of self-perceptions indicators, and only high-score group and mid-score group did not find any significant differences. The test scores of the three groups decreased from high to low while the means of beliefs indicators increased from 2.2828 to 2.9192 . It also indicated that the mean of beliefs indicators of low-score group was significantly different from that of the high-score group.

\subsubsection{Discussion}

The anxiety examined in this study can be seen as foreign language anxiety compounded by test situations, so the inverse correlation showed that both the language anxiety and some potential test anxiety partially affected the subjects' listening performance. This negative correlation between the anxiety levels and listening test 
performance coincided with the previous literature on the relationship between language anxiety and achievements. Studies (Gardener et al., 1987) showed that language anxiety was inversely related to course grades in high school. Another study (Trylong, 1987) detected a negative correlation between anxiety and language achievement for college students. Likewise, Horwitz (1986) also suggested an inverse relationship between anxiety and foreign language achievement.

The results indicated that the test scores of the three groups decreased from high to low while the total anxiety means and the means of three categories of ELAS increased, showing an increase trend of these means with the decrease of test scores, indicating that more successful students were less affected by their listening anxiety than less successful students. Moreover, there were statistically differences in total anxiety means, cognitive symptoms means, affective symptoms means between the high-score students and low-score students, which suggested that students' test performance was negatively affected by listening anxiety. These results were in line with Zuo's (2000) findings that bottom students were more affected by anxiety than top students when they took the Band Four Oral Test.

\subsection{Subjects' Verbal Account of Their English Listening Anxiety}

Eight most anxious students were selected to have individual interviews with the researcher. They were interviewed to offer a better understanding of English listening anxiety, the more anxiety-inducing task of the listening test, and some possible factors associated with foreign language listening anxiety.

Table 12. Descriptions of interview subjects

\begin{tabular}{llll}
\hline Interviewee & Sex & Total anxiety means & Test scores \\
\hline A & Male & 3.97 & Mid \\
B & Female & 3.72 & Mid \\
C & Female & 3.69 & Low \\
D & Female & 3.61 & High \\
E & Female & 3.56 & Mid \\
F & Female & 3.56 & Low \\
G & Female & 3.56 & Mid \\
H & Female & 3.50 & Low \\
\hline
\end{tabular}

\subsubsection{Students' Anxious Symptoms during the Test}

The findings in this study found an increasing trend of overall anxiety levels with the decrease of test scores. Interestingly, Table 12 revealed that among the eight most highly anxious subjects, besides three low-score students, there is still one high-score student. This indicated that although the high-anxiety-level was generally correlated to poor performance, yet exceptions existed. Interviewee D with the high-score confessed during the interview:

The eight subjects all reported cognitive symptoms during the test and self-perceived low listening ability was the most commonly experienced symptoms. The interviewee with the high-score also depicted some cognitive symptoms she experienced during the test: Affective symptoms were also commonly experienced by those selected interviewees. Some of the interviewees admitted that they were also affected by behavioral symptoms, while others said that they were screened from severe ones. The ones experiencing behavioral symptoms reported:

The second task (conversations) was said to be more difficult by all the subjects. But they held much different views about the degree of anxiety inducing by each task. Three of the interviewee subjects thought the task of conversations caused anxiety more easily.

Interestingly, however, the other five interviewees reported the first task (dialogues) to be the more anxiety-inducing one, although they were comparatively easier just because it was the "first" item of test. One of them confessed:

\subsubsection{Students' Explanation of the Reasons of Feeling Anxious in the Test}

The researcher extracted the interview findings and finally detected four possible factors associated with English listening anxiety. See Table 13. 
Table 13. A summary of the reasons of subjects' feeling anxious in the listening test

\begin{tabular}{ll}
\hline 1 & Environmental factors \\
2 & Self-perceived foreign language listening competence \\
3 & Fear of failing the listening course \\
4 & Beliefs about language learning \\
\hline
\end{tabular}

The subjects reported that some environmental elements could lead to their uneasiness during the test. Five of them confessed that they were very much affected by the serious atmosphere of the test.

Besides, some subjects admitted that they were annoyed by some behaviors of the supervising teachers. For example, some teachers would stand beside a certain subject for a long time and move around in the classroom, or even sometimes they would stare at one subject's test paper. All these behaviors could raise the subjects' apprehension and nervousness. Other possible environmental elements associated with anxiety include: earphones did not work well or the recording quality of the tape was not good.

\subsubsection{Discussion}

These findings coincided with what Chen (1997) found in his study: students were very much influenced by learning environment. Self-perceptions can be seen as a critical factor in language learning anxiety and it plays a key role in how students approach acquisition and use of a second language (Armeda, 1988). The present study confirmed this view. The following reports made by the subjects indicated that these high-anxiety-level subjects tended to have lower self-previewed English listening ability.

The subjects' fear of failing the listening course, fitting into Aida's standpoint (1994), resulted in anxiety. They tended to worry a lot about whether they would pass the listening course or not. It might be the surmise that students were afflicted more or less by the fearful feeling of failing the listening course. The subjects' belief about language learning was another factor leading to listening anxiety. Most of the subjects' reported that they had various views about English listening activity.

The findings attested to the study by Young (1991) and Horwitz (1986), who suggested that learner belief about language learning was one of the important sources of language anxiety.

\section{Conclusion}

The study showed that English listening anxiety afflicted most of the subjects in the test. There was a significantly negative correlation between subjects' English listening anxiety levels and their test performance, which meant that the higher score a subject achieved, the less anxious he or she experienced. The cognitive symptoms received the strongest correlation with the test results while the behavioral symptoms, the weakest. The more successful students, in general, were less afflicted by anxiety than unsuccessful students in the English listening test.

The interview further confirmed that the subjects were affected by the three types of anxiety symptoms: cognitive indicator, affective indicator and behavioral indicator. The environmental factors, self-perceived foreign language listening competence, fear of failing the listening course, beliefs about language learning were reported as four major factors leading to English listening anxiety.

Some pedagogical and theoretical implications can be drawn from the findings of the present study. First, teachers should, by means of encouragement and positive comments, try to help students foster a positive self-image and a sense of self-confidence in their listening ability, and develop right beliefs about language learning. Second, teachers should make efforts to reduce environmental symptoms of anxiety. Furthermore, it will be better for teachers to let students listen to some light music or some relaxing material in order to ease their anxiety. Finally, Teachers should avoid some misleading hints, such as always ignoring the bottom students in class and only making eye contact with top students.

\section{Acknowledgements}

This research was supported by the Fundamental Research Funds for the Central Universities of China (2014ZX12).

\section{References}

Aida, Y. (1994). Examinations of Horwitz, and Cope's construct of foreign language anxiety: the case Aida, Y of students of Japanese. The Modern Language Journal, 78, 155-168. http://dx.doi.org/10.1111/j.1540-4781.1994.tb02026.x 
Armeda, C. R., \& Karen, A. (1988). A relational model for managing second language anxiety. TESOL Quarterly, 22, 437-454. http://dx.doi.org/10.2307/3587288

Chen, J. (1997). The relationship between Chinese EFL oral performance and class anxiety. Foreign Language Teaching Abroad, 15-18.

Gardner, R. C., Lalonde. R. N., Moorcroft, R., \& Evers. F. T. (1987). Second Language attrition: the role of motivation and use. Journal of Language and Social Psychology, 6, 29-47.

Horwitz, E. K., \& Young, D. J. (1991). Preliminary evidence for the reliability and validity of a foreign language anxiety scale. Language Anxiety: From Theory and Research to Classroom Implications. Englewood Cliffs, NJ: Prentice Hall, 37-40.

Horwitz, E. K., Horwitz, M. B., \& Cope, J. (1986). Foreign language classroom anxiety. The Modern Language Journal, 70, 125-132. http://dx.doi.org/10.1111/j.1540-4781.1986.tb05256.x

Krashen, S., Omaggio, A., Terell, T., \& Rardin, J. (1992). Thoughts on language anxiety. Foreign Language Annuals, 25, 157-172. http://dx.doi.org/10.1111/j.1944-9720.1992.tb00524.x

MacIntyre, P. D., \& Gardner, R. C. (1991). Investigating language class anxiety using the focused essay $\begin{array}{lllll}\text { technique. } & \text { The }\end{array}$ http://dx.doi.org/10.1111/j.1540-4781.1991.tb05358.x

MacIntyre, P. D., \& Gardner, R. C. (1994). The effects of induced anxiety on three stages of cognitive processing in computerized vocabulary learning. Studies in Second Language Acquisition, 16, 1-17.

Madigan, R., Linton, P., \& Johnson, S. (1996). The Paradox of writing apprehension. In L. Gregg \& E. R. Steinberg (Eds.), Cognitive process in writing (pp. 295-307). Hillsdale, NJ: Lawrence Erlbaum.

McCroskey, J. C., Daly, J. A., Richmond, V. P., \& Falclone, R. L. (1977). Studies of the relationship between communication apprehension and self-esteem. Human Communication Research, 3, 269-277. http://dx.doi.org/10.1111/j.1468-2958.1977.tb00525.x

Oh, J. (1990). On the relationship between anxiety and reading in English as a foreign language among Korean university students in Korea. Unpublished doctoral dissertation, University of Texas, Austin.

Phillips, E. M. (1992). The effects of language anxiety on students' oral test performance and attitudes. The Modern Language Journal, 76, 15-26. http://dx.doi.org/10.1111/j.1540-4781.1992.tb02573.x

Sellers, V. D. (2000). Anxiety and reading comprehension in Spanish as a foreign language. Foreign Language Annals, 33, 512-521. http://dx.doi.org/10.1111/j.1944-9720.2000.tb01995.x

Spielberger, C. D. (1983). Manual for the State-Trait Anxiety Inventory. Palo Alto, California: Consulting Psychologists Press.

Trylong, V. L. (1987). Aptitude, attitudes, and anxiety: A study of their relationships to achievement in the foreign language classroom. Unpublished doctoral dissertation, Purdue University, West Lafayette, Indiana.

Young, D. J. (1991). Creating a low-anxiety classroom environment: what does language anxiety research suggest? Modern Language Journal, 75, 426-437. http://dx.doi.org/10.1111/j.1540-4781.1991.tb05378.x

Young, D. J. (1992). Language anxiety from the foreign language specialist's perspective: interviews with Krashen, Omaggio Hadley, Terrell, and Rardin. Foreign Language Annuals, 25, 157-172. http://dx.doi.org/10.1111/j.1944-9720.1992.tb00524.x

Zuo, H. (2003). The relationship between Chinese EFL students' oral performance and language anxiety when they took the TEM4 oral test. Unpublished MA thesis, Nanjing University.

\section{Copyrights}

Copyright for this article is retained by the author(s), with first publication rights granted to the journal.

This is an open-access article distributed under the terms and conditions of the Creative Commons Attribution license (http://creativecommons.org/licenses/by/3.0/). 